\section{Melioidose numa pequena comunidade rural do Ceará}

\section{Melioidosis in a little rural community of Ceará State}

\section{Senhor Editor:}

Antes de tudo, gostaríamos de agradecer a atenção e a confiança que 0 senhor nos tem dispensado todas às vezes que enviamos algum trabalho à RSBMT.

Respondendo à sua correspondência de 2 de fevereiro do corrente, sobre comunicação recebida do colega Dr. Walter Tavares, que questiona alguns fatos relacionados com nosso trabalho recentemente publicado na Revista, no número de janeiro/fevereiro de 2005, gostaríamos de comunicar-lhe o que se segue:

0 Dr. Walter Tavares questiona o motivo de não havermos referido à publicação do Dr. (Dra?) Dione B. Rolim, intitulada "Melioidose numa pequena comunidade rural do Ceará: investigação epidemiológica" ( Rev Soc Bras Med Trop 2004: 37 ( supl I) : 66-67). Gostaria de lembrar ao senhor a missiva em anexo, quando lhe devolvemos o nosso trabalho revisado, que ele foi recebido pela RSBMT em 11/11/2003 e só foi aceito em 1/11/2004, um ano depois, conforme saiu na Revista. Naquela carta nos justificávamos aos revisores por apenas citarmos a comunicação pessoal da Doutora Miralles, do Laboratório Central da Secretaria Estadual de Saúde Pública do Ceará, LACEM, que posteriormente publicou com colaboradores 0 trabalho "Burkholderia pseudomallei: a case report of a human infection in Ceará, Brazil" (Rev. Inst. Med. Trop. S. Paulo vol. 46 número l, São Paulo Jan/Feb. 2004), pelo fato de que 0 referido trabalho encontrava-se no prelo para publicação, na data em que 0 nosso estava sendo revisado. Não poderíamos por isso citar um trabalho que ainda não fora publicado, mas a comunicação pessoal da Dra. Miralles ficou registrada no nosso texto. Pelo mesmo motivo, não poderíamos citar em nosso artigo enviado à RSBMT em 2003, um trabalho apresentado em março de 2004 no XL Congresso da Sociedade Brasileira de Medicina Tropical em Aracaju, no qual participamos como co-autores, que seria posteriormente divulgado no Suplemento citado pelo Dr. Walter Tavares.

Em relação a outro ponto questionado, que não haveríamos mencionado a origem do caso, chamo a atenção para a referência número 10 do nosso trabalho, onde citamos o site da Secretaria Estadual de Saúde do Estado do Ceará, www.saude.ce.gov.br, acessado em 13/03/2003, cujo portal de Serviços e Informações apresenta 0 seguinte título: "População de Tejuçuoca não corre risco de epidemia." Nele estão descritos os casos ocorridos com os irmãos acometidos da patologia, naquela cidade, citados na última linha da seção Relato do Caso. No nosso artigo, infelizmente, e aqui nos penitenciamos, a citação nesta linha deveria ser de óbito ${ }^{10}$ ao invés de óbito ${ }^{1}$, pois foi trocada com a da terceira linha da introdução (Austrália ${ }^{11}$ sena 0 correto ao invés de Austrália ${ }^{1011}$ ).

Ademais, os dois trabalhos têm abordagem completamente diversa sobre 0 caso e se complementam, constituindo-se num caso de intercessão temporal tendo em vista 0 longo mas às vezes necessário período de submissão a análises e revisões de artigos, por parte de revistas que buscam preservar critérios de qualidade.

Sem mais no momento, esperando havermos esclarecido os questionamentos do Dr. Walter Tavares, voltamos a agradecer sua consideração.

\section{Marcus Davis Machado Braga ${ }^{1}$ Paulo Roberto Carvalho de Almeida ${ }^{I}$}

1. Departamento de Patologia e Medicina Legal da Faculdade de Medicina da Universidade Federal do Ceará, Fortaleza, CE.

\section{A leishmaniose visceral é uma doença endêmica em Recife, Pernambuco?}

\author{
Is visceral leishmaniasis an endemic \\ disease in Recife, Pernambuco?
}

\section{Senhor Editor:}

0 artigo "Leishmaniose visceral: estudo de flebotomíneos einfecção canina em Montes Claros, Minas Gerais" de autoria de Monteiro e cols", publicado no volume 38, número 2, marçoabril, de 2005, aborda aspectos da leishmaniose visceral (IV) em Montes Claros, contribuindo de maneira significativa para 0 conhecimento da situação epidemiológica da doença neste município de Minas Gerais. No estudo em questão, os autores investigam a soroprevalência canina em dez bairros, nos quais a LV é endêmica. Com base nos resultados dos testes sorológicos, os autores concluem "que a prevalência da leishmaniose visceral canina continua sendo um grande problema no município de Montes Claros ${ }^{4 \prime}$. É preciso registrar que os resultados revelam um problema, além da questão da soroprevalência canina por si só. Esses achados, associados aos encontrados em estudos previamente realizados em Montes Claros $^{3}$, demonstram que a eliminação sistemática de cães soropositivos não tem sido capaz de reduzir a soroprevalência canina. Logo, seria importante chamar a atenção para algumas questões básicas: A eliminação de cães soropositivos será capaz de reduzir a incidência da doença no homem, neste município? 
Como está sendo avaliado o custo-efetividade e o custo-benefício dessa medida de controle? Estas são questões chaves que justificam a realização de mais estudos em Montes Claros.

Outro aspecto, não menos importante, abordado no estudo ${ }^{4}$, foi o comportamento da população de flebotomíneos nos dez bairros previamente selecionados. Os autores estudaram aspectos cruciais sobre o comportamento dos flebotomíneos, como endofilia e exofilia. Toda e qualquer estratégia de controle vetorial a ser empregada em programas de controle das leishmanioses, deveria basear-se no prévio conhecimento do comportamento da população de flebotomíneos. Tão importante quanto aos estudos sobre endofilia e exofilia, seria avaliar se os flebotomíneos costumam alimentar-se dentro (endofagia) ou fora (exofagia) dos domicílios. Da mesma maneira, é preciso saber se a população de Lutzomyia longipalpis apresenta, ou não, concordância gonotrófica. Espécies que apresentam discordância gonotrófica precisam de dois ou mais repastos sangǘneos para completar o desenvolvimento dos ovos. Esta observação é extremamente importante do ponto de vista epidemiológico, pois significa que a fêmea irá procurar mais de um hospedeiro para completar o ciclo gonotrófico. 0 conhecimento prévio sobre 0 grau de endofilia x exofilia, endofagia x exofagia, concordância x discordância gonotrófica, bem como sobre a sazonalidade dos flebotomíneos comprovadamente vetores, ajudariam a definir, de forma mais precisa, os períodos de maior risco de adquirir a infecção em áreas endêmicas.

Afora os aspectos positivos já mencionados, é preciso chamar a atenção para um equívoco. № quarto parágrafo da página 148, os autores afirmam: “ ...com a doença instalada definitivamente em cidades de médio e grande porte, como Teresina, Recife, Rio de Janeiro, Salvador, Belo Horizonte, Montes Claros, Januário, entre outras"4. Essa afirmação não está correta. De fato, existem casos autóctones registrados em municípios da região metropolitana do Recife, tais como Itamaracá e Paulista, mas não na Cidade do Recife. Não obstante, alguns pacientes residentes em municípios do interior de Pernambuco, migram para capital em busca de tratamento nos hospitais de referência, e acabam por ser, erroneamente, eventualmente notificados como casos de Recife. Atrelado a isto, a presença de populações de Lutzomyia longipalpis ainda não foi confirmada no Recife 2 . Logo, todos os casos registrados nesta cidade podem ser até hoje, categoricamente classificados como casos alóctones.

Até onde sabemos, também não existem casos autóctones na cidade de Salvador, mas sim na região metropolitana. É interessante esse registro, pois não conseguimos explicar por que a LV ocorre de forma endêmica em municípios circunvizinhos de Salvador e Recife, sem que ocorra nestes últimos. 0 assunto foi comentado pelo Prof. Carlos Henrique Nery Costa ${ }^{1}$, UFPI, durante 0 VI Congresso Brasileiro de Epidemiologia, realizado em Recife em 2004. Várias hipóteses foram aventadas, durante uma breve discussão, porém nenhuma foi capaz de explicar a razão da não existência do ciclo zoonótico da LV nestes dois municípios.

No Brasil, a expansão da LVé fato demasiadamente conhecido. A doença se perpetua de forma paradigmática, difundindo-se geograficamente numa velocidade preocupante. Em parte, isso reflete uma melhoria no Sistema de Informação de Agravos de Notificação ( SINAN) . Por outro lado, ilustra o baixo impacto das atuais estratégias de controle. Trabalhos dentro do escopo deste de Montes Claros e daqueles realizados em cidades como Teresina e Campo Grande, só para ficar com dois outros exemplos, devem ser cada vez mais encorajados e apoiados, como vem fazendo a Secretaria de Vigilância em Saúde/Ministério da Saúde, a fim de estabelecer o melhor planejamento e efetividade das ações de controle desta zoonose no Brasil.

\section{REFERÊNCIAS BIBLIOGRÁFICAS}

1. Costa CHN. Urbanização da leishmaniose visceral no Brasil: caracterização e especulações ontogenéticas. In: Anais do VI Congresso Brasileiro de Epidemiologia. Recife, 1 CD-ROM, 2004.

2. Dantas-Torres F, Faustino MAG, Alves LC, Acioli R, Lima OC. Classificação do município do Recife quanto à transmissão da leishmaniose visceral canina. Revista Brasileira de Parasitologia Veterinária 23: 234, 2004.

3. França-Silva JC, Costa RT, Siqueira AM, Machado-Coelho GL, Costa CA, Mayrink W, Vieira EP, Costa JC, Genaro 0, Nascimento E. Epidemiology of canine visceral leishmaniasis in the endemic area of Montes Claros municipality, Minas Gerais State, Brazil. Veterinary Parasitology 111: 161173, 2003.

4. Monteiro EM, França-Silva JC, Costa RT, Costa DC, Barata RA, Paula EV, Machado-Coelho GL, Rocha MF, Fortes-Dias CL, Dias ES. Leishmaniose visceral: estudo de flebotomíneos e infecção canina em Montes Claros, Minas Gerais. Revista da Sociedade Brasileira de Medicina Tropical 38: 147-152, 2005.

\section{Filipe Dantas-Torres ${ }^{1} e$ Sinval Pinto Brandão-Filho ${ }^{I}$}

1. Centro de Pesquisas Aggeu Magalhães da Fundação Oswaldo Cruz, Recife, Pernambuco.

\section{Reflexões sobre a Política Global de Controle de Hanseníase}

\section{Considerations about Global Policy for Leprosy Control}

\section{Senhor Editor:}

A Sociedade Brasileira de Dermatologia (SBD), como comunidade científica nacional, solidariza-se com a comunidade científica internacional, contra essa marcha da Organização Mundial de Saúde (OMS) pela eliminação da hanseníase. Deveríamos aprender com a malária que precisou de décadas para e voltar ao controle e abandonar a idéia da erradicação.

№ Brasil, a Sociedade Brasileira de Dermatologia, já se posicionou oficialmente ao Ministério da Saúde, não concordando com alterações que vêm sendo feitas na política nacional de eliminação da hanseníase. A resposta do Ministério foi exatamente como a OMS agiu na Aliança Global para a 